\title{
Understanding the pathways leading to socioeconomic inequalities in HIV testing uptake in 18 sub-Saharan African countries: a mediation analysis
}

\author{
Pearl Anne Ante-Testard ${ }^{1,2 \S}$, Mohamed Hamidouche ${ }^{1,2}$, Bénédicte Apouey ${ }^{3}$, Rachel Baggaley ${ }^{4}$, \\ Joseph Larmarange ${ }^{5}$, Tarik Benmarhnia ${ }^{6}$, Laura Temime ${ }^{1,2}$, Kévin Jean ${ }^{1,2,7}$
}

${ }^{1}$ Laboratoire MESuRS, Conservatoire national des Arts et Métiers, Paris, France

${ }^{2}$ Unité PACRI, Institut Pasteur, Conservatoire national des Arts et Métiers, Paris, France

${ }^{3}$ Paris School of Economics - CNRS, Paris, France

${ }^{4}$ Department of HIV and Global Hepatitis Programme, WHO, Geneva, Switzerland

${ }^{5}$ Centre Population et Développement, Institut de Recherche pour le Développement, Université de Paris, Inserm, Paris France

${ }^{6}$ Herbert Wertheim School of Public Health and Human Longevity Science \& Scripps Institution of Oceanography, University of California San Diego, San Diego, California, USA

${ }^{7}$ MRC Centre for Global Infectious Disease Analysis, Department of Infectious Disease Epidemiology, Imperial College London, United Kingdom

$\S_{\text {Corresponding author: Pearl Anne Ante-Testard }}$

Laboratoire MESuRS, Conservatoire national des Arts et Métiers

292 rue Saint Martin, 75003, Paris, France

pearl-anne.ante@lecnam.net

Keywords: HIV, HIV testing, socioeconomic inequalities, health inequalities, sub-Saharan Africa, mediation analysis

NOTE: This preprint reports new research that has not been certified by peer review and should not be used to guide clinical practice. 1 


\section{Abstract}

\section{Introduction:}

Although socioeconomic inequalities in HIV prevention, testing and treatment services have been well documented, their drivers remain poorly understood. Understanding the different pathways between socioeconomic position and HIV testing across different countries could help designing tailored programs aimed at reducing such inequalities.

\section{Methods:}

We analysed data from Demographic and Health Surveys conducted between 2010 and 2018 in 18 sub-Saharan African countries (Burkina Faso, Cameroon, Côte d'Ivoire, Congo DR, Ethiopia, Guinea, Kenya, Lesotho, Liberia, Malawi, Mali, Niger, Rwanda, Senegal, Sierra Leone, Tanzania, Zambia and Zimbabwe). Using a potential outcomes framework and the product method, we decomposed the total effect linking wealth and recent ( $<12$ months) HIV testing into i) direct effects, and ii) indirect effects, via demand-related (related to individual's ability to perceive need for care and inclination to seek care) or supply-related (related to individual's ability to reach, pay for and engage in health care) mediators. Multivariable gender-specific modified Poisson models were fitted to estimate proportions mediated, while accounting for exposure-mediator interaction when present.

\section{Results:}

A total of 392,044 participants were included in the analysis. Pro-rich wealth-related inequalities were observed in a majority of countries, with nine countries with high levels of inequalities among women and 15 countries among men.

The indirect effects of each mediator varied greatly across countries. The proportion mediated tended to be higher for demand-related than for supply-related mediators. For instance, among women, HIV-related knowledge was estimated to mediate up to $12.1 \%$ of inequalities in Côte d'Ivoire; this proportion was up to $31.5 \%$ for positive attitudes toward people living with HIV (PLHIV) in Senegal. For the four supply-related mediators, the proportion mediated was systematically below 7\%. Similar conclusions were found when repeating analyses on men for 
medRxiv preprint doi: https://doi.org/10.1101/2021.09.18.21263768; this version posted October 22, 2021. The copyright holder for this preprint

(which was not certified by peer review) is the author/funder, who has granted medRxiv a license to display the preprint in perpetuity.

It is made available under a CC-BY-NC-ND 4.0 International license.

the demand-related mediators, with higher proportions mediated by positive attitudes toward PLHIV (up to $39.9 \%$ in Senegal).

\section{Conclusions:}

Our findings suggest that socioeconomic inequalities in HIV testing may be mediated by the demand-side more than supply-side characteristics, with important variability across countries. Overall, the important inter-country heterogeneity in pathways of socioeconomic inequalities in HIV testing illustrates that addressing inequalities requires tailored efforts as well as upstream interventions.

A French version of the abstract is available upon request from the corresponding author. 
medRxiv preprint doi: https://doi.org/10.1101/2021.09.18.21263768; this version posted October 22, 2021. The copyright holder for this preprint (which was not certified by peer review) is the author/funder, who has granted medRxiv a license to display the preprint in perpetuity.

It is made available under a CC-BY-NC-ND 4.0 International license .

\section{Introduction}

HIV continues to affect many lives globally especially in sub-Saharan Africa (SSA) which accounts for 59\% of new HIV infections in 2019 [1] making HIV prevention and treatment essential, particularly in this region. HIV testing has played a crucial role in the prevention and management of HIV/AIDS as the entry point that links individuals to prevention and treatment services.

Routine offer of HIV testing in health settings, such as antenatal clinics was recommended by the World Health Organization in 2007 [2], which changed the profiles of testing users and increased uptake in HIV testing [3]. However, in spite of the significant progress in reducing HIV incidence over the past decade in SSA, HIV incidence has not declined sufficiently to reach the UNAIDS 90-90-90 fast-track goals by 2020 and the Sustainable Development Goal of ending the AIDS epidemic by 2030 [4]. A modelling study that investigated the progress towards the first 90 (i.e., $90 \%$ of PLHIV will know their status) found that $84 \%$ of PLHIV in SSA knew their status by 2020, with proportions consistently lower in Western and Central Africa (WCA, 67\% and $70 \%$, respectively) than in Eastern and Southern Africa (ESA, 86\% and 90\%, respectively) [5]. These left a gap of around 3.8 million PLHIV left undiagnosed in SSA [5].

Health inequalities that favour the wealthiest subgroups have also persisted in most SSA countries, especially in WCA [6]. Studies found that people with higher socioeconomic position (SEP), and those who were employed, living in urban areas and had heard about HIV and AIDS were associated with better knowledge of HIV status and were more likely to seek testing [7-13]. Potential drivers of these inequalities include HIV-related knowledge, HIV stigma, distance to care and cost of services, among many others. A study found that cost of services, and physical distance between health facilities and service user's residence were the most significant supplyside barriers in accessing obstetric care in sub-Saharan Africa [14]. We hypothesize these drivers to also be important barriers in accessing HIV testing services. Documenting such mechanisms can be useful in understanding the role of each factor in driving such inequalities.

Despite the literature in socioeconomic inequalities in HIV testing, few studies have explored their possible underlying mechanisms. Such studies are timely though to help better orientate 
testing strategies in order to reach the first 95 of the 2030 UNAIDS 95-95-95 targets and to ensure "no one is left behind". In this study, we analysed population-based surveys to understand mediating factors linking SEP and HIV testing uptake at the individual level.

\section{Methods}

\section{Data and Study Design}

We analysed data from the Demographic and Health Surveys (DHS) conducted between 2010 and 2018 to understand the role of different mediating factors in the pathway between SEP and recent ( $<12$ months) HIV testing uptake.

The DHS are publicly available nationally representative population-based surveys, conducted regularly in low- and middle-income countries (LMIC), collecting data on a wide range of objective and self-reported health indicators including data on HIV/AIDS, using a two-stage sampling design [15]. All women aged 15-49 years are all eligible in all households and, in some surveys, men aged 15-54/59 from a sub-sample are also eligible to participate (https://dhsprogram.com/). The national implementing agencies or research institutes that conducted the surveys were responsible for ethical clearance which assured informed consent from the participants prior to their involvement and guaranteed confidentiality of information [16]. Those who consented are interviewed face-to-face by trained interviewers using a standardized questionnaire that includes items on different sociodemographic characteristics, maternal and reproductive health, and HIV-related questions [15].

Country sample was based on convenience sampling (data available as of February 2021) that was slightly extended from a previous study [6]. In total, we analysed $10 \mathrm{WCA}$ countries (Burkina Faso, Cameroon, Côte d'Ivoire, Cameroon, Congo DR, Guinea, Liberia, Mali, Niger, Senegal and Sierra Leone) and eight ESA countries (Ethiopia, Kenya, Lesotho, Malawi, Rwanda, Tanzania, Zimbabwe and Zambia).

\section{Variables}

Socioeconomic Position 
We defined participant SEP based on the DHS wealth index, a composite measure of household wealth based on living standards such as household assets and characteristics [17]. More specifically, we used the wealth rank of the participants in the country-specific cumulative distribution of the wealth index, a continuous variable ranging from 0 to 1 .

\section{Outcome variable}

The outcome of interest was the self-report of recent (<12 months) HIV testing.

\section{Mediators}

We selected six potential mediators available in the DHS that we hypothesized to be in the pathway between wealth and recent HIV testing uptake based on the literature. We categorized these mediators in two categories based on a principal component analysis for women (Figure S1). The first category of factors referred to the individual's ability to perceive the need for care and inclination to seek care [18] (i.e., HIV-related knowledge and positive attitudes toward PLHIV). The second mediators' category included factors that characterize the ability to reach, pay for, and engage in health care [18] (i.e., reporting no distance-related problem to seek care, reporting no money-related problem to seek care, no permission needed from spouse/partner to seek a doctor and no/single difficulty in seeking care). For simplicity, we labelled the first category demand-related and the second category supply-related mediators. Supply-related variables were only available for women in the DHS.

All mediators were coded as binary variables with favourable responses coded as 1 . Complete descriptions of these variables and how they were constructed can be found in Table S1.

\section{Confounders}

The confounders that we identified a priori were age (15-24, 25-34, 35 and above), type of residence (urban and rural) and family situation (in a union, single and widowed/separated).

\section{Statistical analysis}

For each country, we estimated the proportion of the favourable level of each mediator among the richest and the poorest wealth quintiles while accounting for the survey design. 
To compute the effect estimates, we fitted multivariable modified Poisson regressions while accounting for the survey design and adjusting for confounders [19]. We estimated socioeconomic inequalities in recent HIV testing uptake by estimating the total effect (TE) of wealth on recent testing (Equation 1).

$$
\mathrm{P}(\text { recent HIV testing })=f(\text { wealth }, \text { confounders })(\text { Equation } 1)
$$

Outcome model:

$\mathrm{P}($ recent HIV testing $)=f($ wealth, mediator, EM interaction, confounders $)($ Equation 2$)$

Mediator model:

$$
\mathrm{P}(\text { mediator })=f(\text { wealth }, \text { confounders })(\text { Equation } 3)
$$

We applied different mediator and outcome models (Equations 2 and 3) using the product method based on the potential outcomes framework [20,21] to explore different pathways linking wealth and recent HIV testing uptake through demand-related and supply-related mediators. We assumed that these mediators of interest to do not influence one another in the analysis. We considered four assumptions in this analysis: (1) no unmeasured exposure - outcome confounding, (2) no unmeasured mediator - outcome confounding, (3) no unmeasured exposure - mediator confounding, and (4) none of the mediator - outcome confounder is itself affected by the exposure [22]. Figure 1 shows the Directed Acyclic Graph (DAG) of the pathway and effect estimates that we are interested in. 


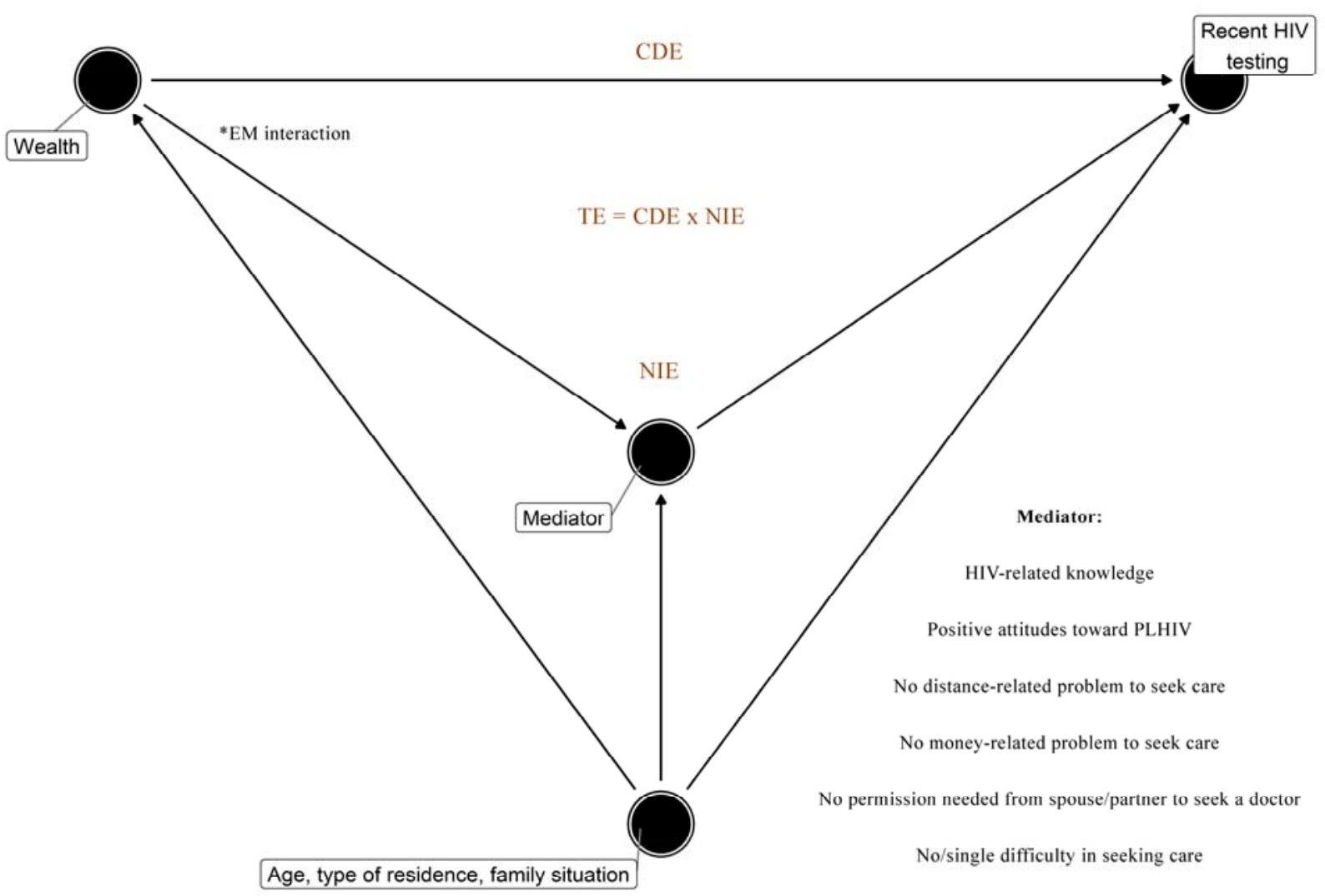

Figure 1. DAG illustrating the pathway between wealth and recent ( $<12$ months) HIV testing through each mediator while adjusting for confounders (i.e., age, type of residence and family situation) and exposure-mediator interaction when present $(*)$. The TE of wealth on recent HIV testing could be disentangled into the CDE and the NIE. TE: Total Effect. CDE: Controlled Direct Effect. NIE: Natural Indirect Effect. EM: Exposure-mediator.

The TE of wealth on recent HIV testing was decomposed into the controlled direct effect (CDE) and the natural indirect effect (NIE). By using coefficients from the outcome and mediator models (Equations 2 and 3, respectively), we estimated the CDE and NIE. The CDE is the effect of the exposure on the outcome, while the mediator is set to a pre-specified level uniformly over the entire population [21]. Here, we pre-specified the level of the mediator to a favourable level. The NIE represents the change in the outcome when SEP is held constant $(\mathrm{X}=\mathrm{x})$ and the mediator changes to what it would have been for a change in the other SEP category $(\mathrm{X}=\mathrm{x} *)$ $[21,23]$. 
We also accounted for exposure-mediator interaction when present to calculate the CDE and NIE by following the formulas from Valeri and Vanderweele [21] (Text S1). By using the CDE and NIE, we estimated the proportion mediated (PM, in \%) which is the proportion of the total effect of the exposure on the outcome that is mediated (Text S1). The PM captures how important the pathway is through the mediator in explaining the observed effect of the exposure on the outcome (i.e., TE) [24].

In order to focus on settings in which socioeconomic inequalities were substantial before decomposing such effects into CDE and NIE, we established a cut-off based on the total effect, with a Prevalence Ratio $(\mathrm{PR}) \geq 1.5$.

We bootstrapped the $95 \%$ confidence interval (CI) with 1000 replications. All analyses were conducted using $\mathrm{R}$ version 4.0.3.

\section{Results}

\section{Characteristics of Study Population}

Data were collected from 392,044 participants, 261,935 female participants and 130,109 male participants. Table 1 and Table S2 illustrate the survey and participants characteristics while accounting for survey design and sampling weights. Overall, 93-100\% of eligible women were successfully interviewed, and 86-100\% of men (Table S2).

In many of the countries, female and male participants lived in rural areas (except in Côte d'Ivoire, Cameroon and Liberia among both genders, and in Senegal among males). They were either married or cohabitating except in Cameroon, Senegal and Lesotho where most males were single (Table S2).

Table 1 shows that around $18 \%-45 \%$ of the female participants and $17 \%-40 \%$ of the male participants had comprehensive HIV-related knowledge in ESA countries compared to 1\%-32\% and 13\%-26\% among female and male participants, respectively, in WCA countries. Moreover, the proportion of participants with positive attitudes toward PLHIV were lower in WCA countries (around 15\%-57\% among females and 18\%-51\% males) compared to ESA countries 
(about 36\%-84\% among females and 45\%-86\% among males). In terms of the supply-related variables, most women reported no supply-related problems except in Burkina Faso, Côte d'Ivoire, Cameroon, Congo DR, Guinea, Niger and Sierra Leone in WCA (where a majority of women reported money-related problems in seeking care), and in Ethiopia, Malawi and Zambia in ESA (where a majority of women reported distance-related and money-related problems in seeking care). Most female participants did not need permission from spouse/partner to seek a doctor in all countries except in Zambia.

Self-reported recent HIV testing uptake among female and male participants in WCA was lowest in Niger (8.4\% and 2.7\%, respectively) and highest in Cameroon (40\% and 35\%, respectively). Meanwhile in ESA, uptake among women and men was lowest in Ethiopia (21.2\% and 19.7\%, respectively) and highest in Kenya (67.9\% and 57.5\%, respectively).

\section{Socioeconomic Inequalities in HIV Testing}

Figure 2 illustrates that the richest were more likely to have comprehensive HIV-related knowledge, have positive attitudes toward PLHIV and were less likely to report supply-related problems. We also observed different magnitudes across countries and mediators.

Table 2 shows the total effect of wealth on recent HIV testing which was the effect estimate we used to measure wealth-related inequalities (Equation 1). We estimated the adjusted PRs of recent HIV testing between the richest and the poorest participants while accounting for confounders. Applying the cut-off of PR $\geq 1.5$ led us to keep nine countries for women and 15 countries for men in our final mediation analyses.

Levels of wealth-related inequalities vary greatly by country and gender with pro-rich inequalities in HIV testing in most countries. Inequalities tended to be higher among men than women. Wealth-related inequalities were markedly observed in WCA countries. Among women, the highest wealth-related inequalities were in Congo DR where the prevalence of recent testing among the richest women was 12.14 (95\% CI 7.34 - 20.08) times greater than among the poorest women. Meanwhile in men, the highest level of inequality was in Niger where the prevalence of recent testing among the richest men was 46.04 (10.47 - 202.43) times greater than among the poorest men. 
Table 1. Survey and population characteristics, by country and gender.

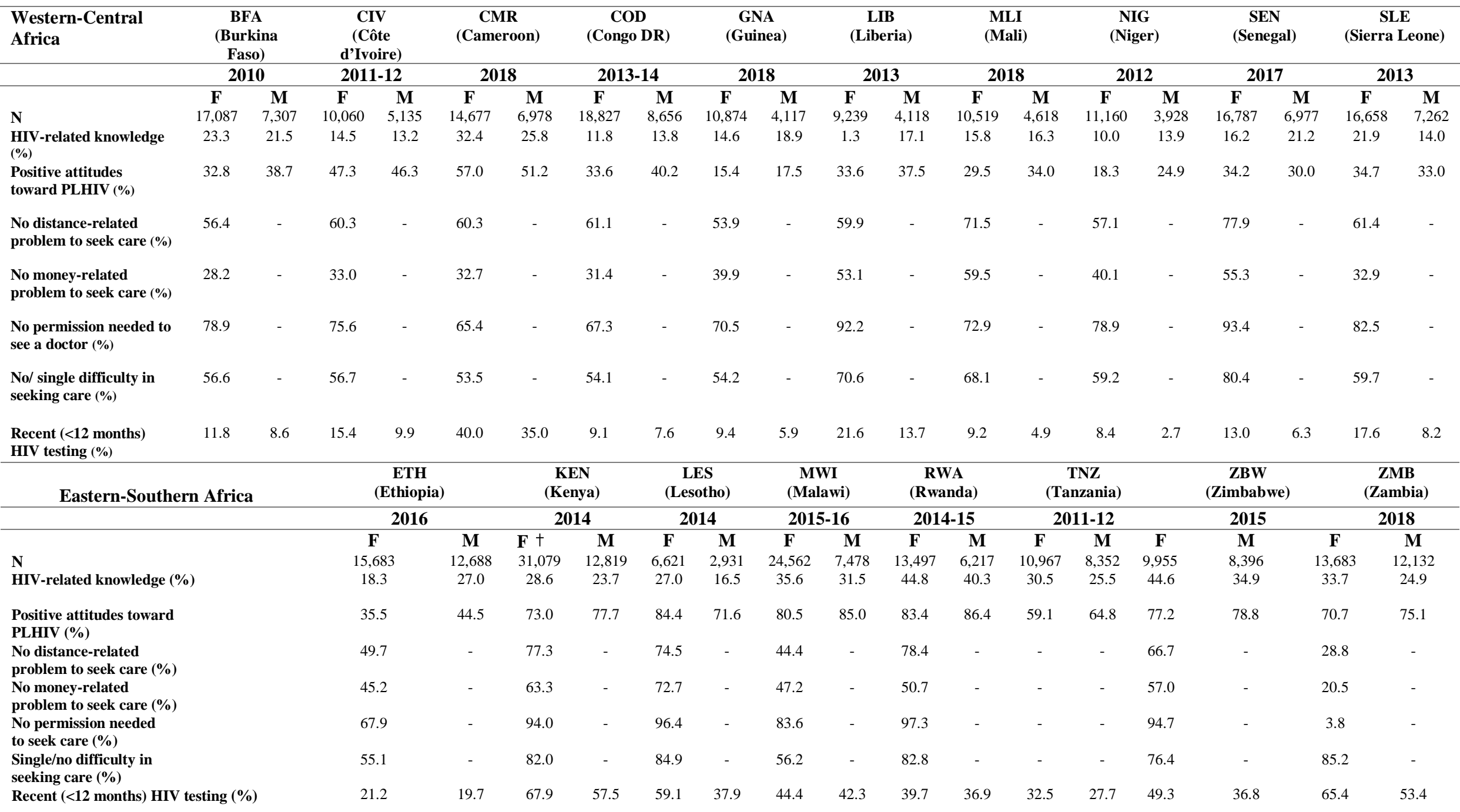

Abbreviations: F, female; M, male, $\mathrm{N}$, total number.

† Women: 31,079 (15-49 years of age: all version); Women: 14,741 (15-49 years of age: full version); Women: 16,338 (15-49 years of age: short version). 


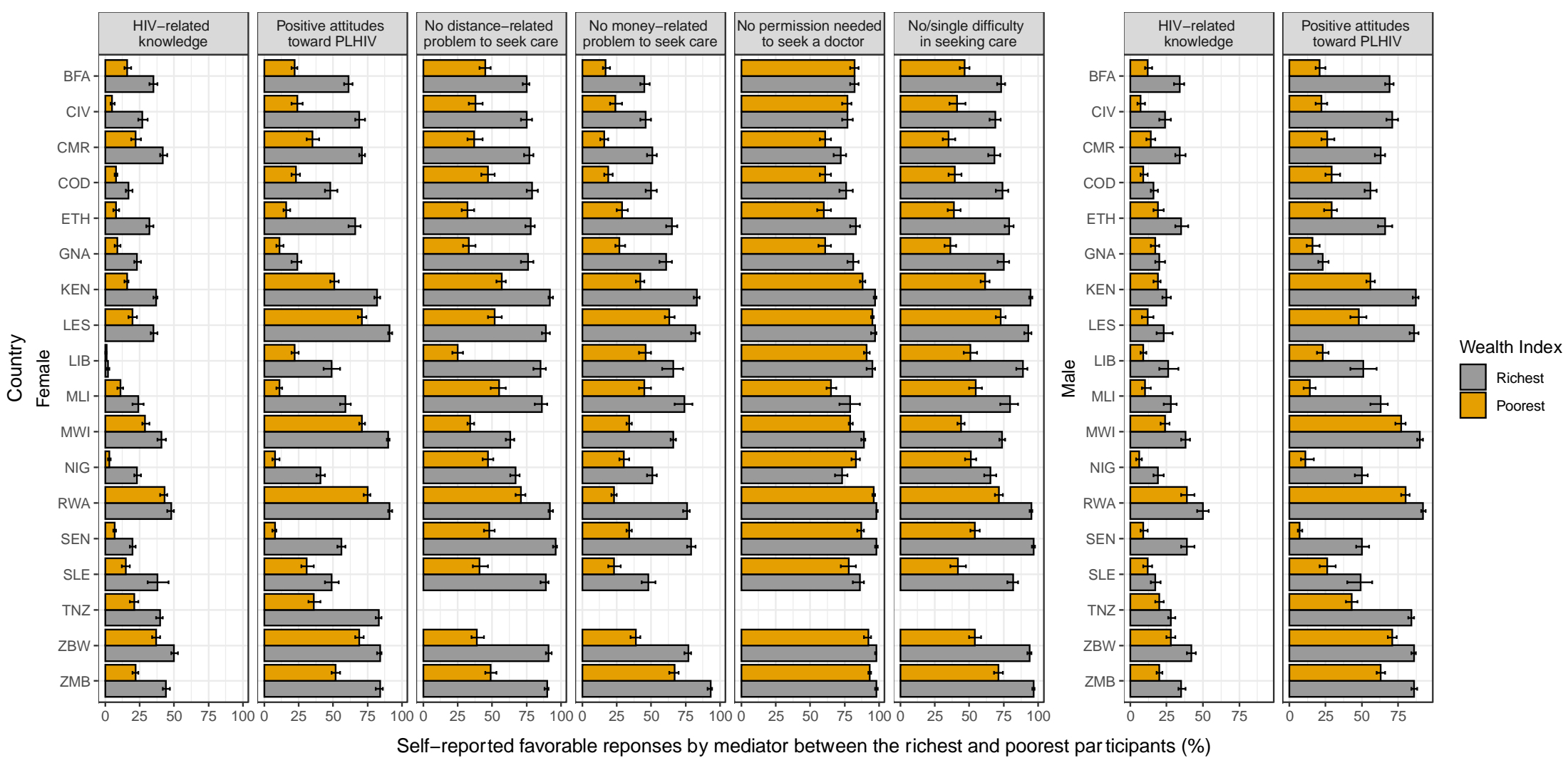

Figure 2. Path from exposure to mediator. Proportion of the richest and poorest participants who self-reported favourable levels of the mediator in 18 sub-Saharan African countries, stratified by gender. Refer to Table 1 for full country names. 
Table 2. Total effect of wealth on recent HIV testing. Adjusted prevalence ratios of recent HIV testing between the richest and poorest participants (stratified by gender), while accounting for confounders. Bold fonts indicate that the model is statistically significant and eligible (PR $\geq 1.5)$, grey colours indicate that the model is significant but ineligible, and normal fonts indicate that the model is not significant. Refer to Table 1 for full country names.

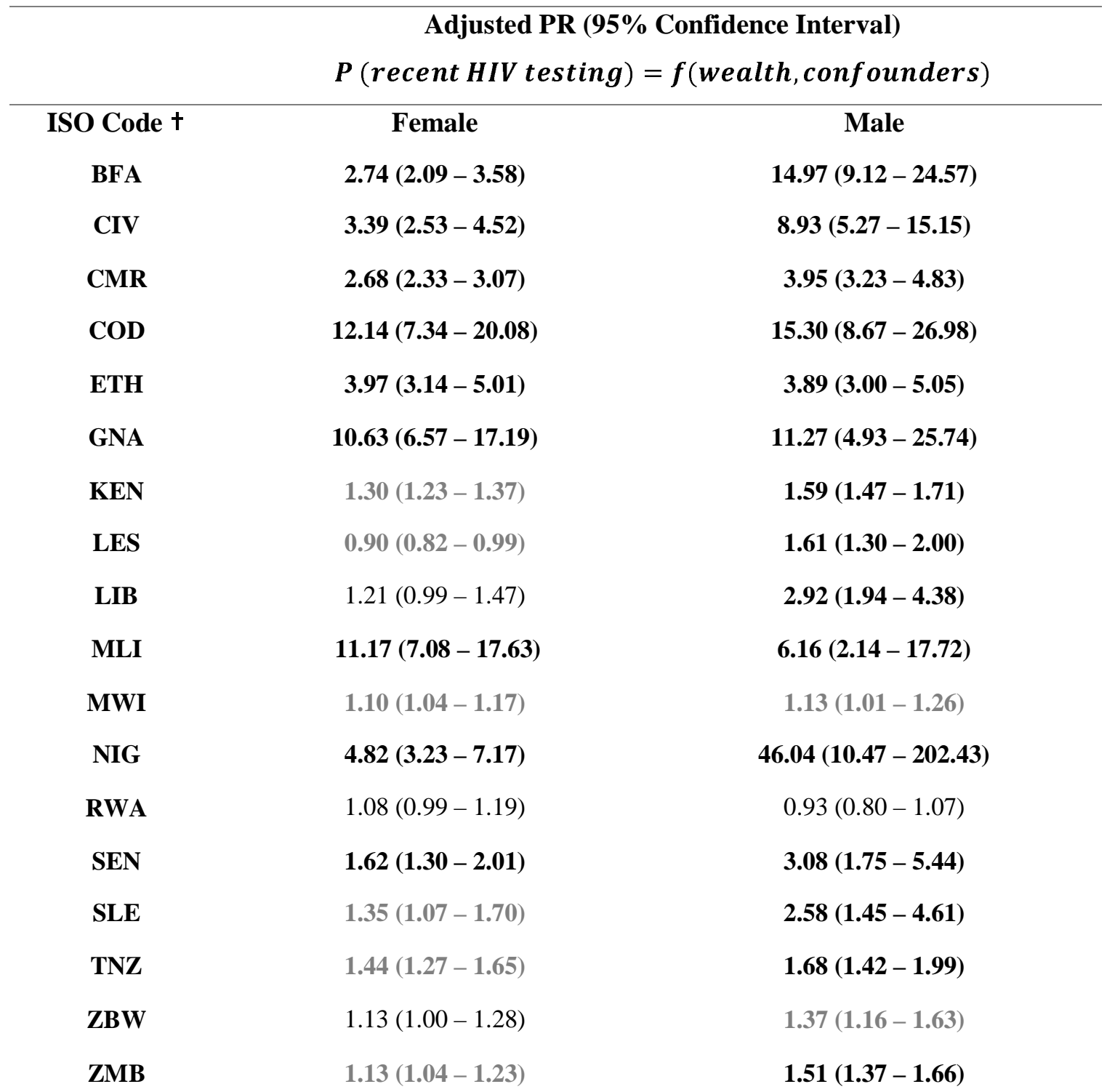

Abbreviations: PR, Prevalence Ratio; P, probability; ISO, International Organization for Standardization. † Refer to Table 1 for full country names. 
medRxiv preprint doi: https://doi.org/10.1101/2021.09.18.21263768; this version posted October 22, 2021. The copyright holder for this preprint (which was not certified by peer review) is the author/funder, who has granted medRxiv a license to display the preprint in perpetuity.

It is made available under a CC-BY-NC-ND 4.0 International license.

\section{Mediated Effects}

Pathways from exposure to each mediator based on Figure 1 were explored (Table S3). Among the eligible models (i.e., with sufficient levels of inequalities) in Table 2, we observed that wealth was associated with majority of the mediators except for HIV-related knowledge among men in Sierra Leone, positive attitudes toward PLHIV among men in Guinea and no permission from spouse/partner needed to seek a doctor in Burkina Faso, Côte d'Ivoire, Liberia and Niger among women (Table S3). The paths from each mediator to outcome were also explored (Figure S2 and Table S4). In all eligible countries except Lesotho, all mediators were positively associated with recent HIV testing (Table S4).

There was heterogeneity in the importance and role of each mediator in the pathway between wealth and recent testing across countries and gender groups (Figure 3). Demand-related mediators tended to have higher proportions mediated compared to supply-related mediators in women, with magnitudes varying across countries. For example, among women, the total effect of wealth on recent HIV testing uptake was mediated by positive attitudes toward PLHIV by $31.46 \%(95 \%$ CI $20.14 \%-53.37 \%)$ in Senegal, but only by $4.34 \%(-0.12 \%-8.78 \%)$ in Niger. In other words, we could also say that wealth-related inequality in testing among women in Senegal could be explained by positive attitudes toward PLHIV by $31.46 \%$ (95\% CI 20.14\%-53.37\%). Meanwhile, in Côte d'Ivoire, wealth-related inequalities in testing could be explained by HIVrelated knowledge by $12.14 \%$ (7.28\%-17.82\%), while in Congo DR by only $0.34 \%(-1.48 \%-$ 2.05\%). Supply-related mediators tended to have lower proportions mediated in majority of the countries except in Burkina Faso, Congo DR, Guinea, and Senegal in which reporting no moneyrelated problem mediated slightly more or almost similarly than HIV-related knowledge.

Among men, having positive attitudes toward PLHIV tended to mediate the total effect of wealth on testing more with a range between $-1.58 \%$ (95CI -6.81\%-2.88\%) in Ethiopia and 39.85\% (26.68\%-61.66\%) in Senegal than HIV-related knowledge that ranged between $-2.27 \%(-6.69 \%$ $0.98 \%$ ) in Ethiopia and $11.63 \%$ (5.21\%-19.87\%) in Côte d'Ivoire. A negative proportion mediated means that the CDE and NIE were in opposite direction. Figure S3 shows small reductions in wealth-related inequalities in a few countries after controlling for the mediators. 


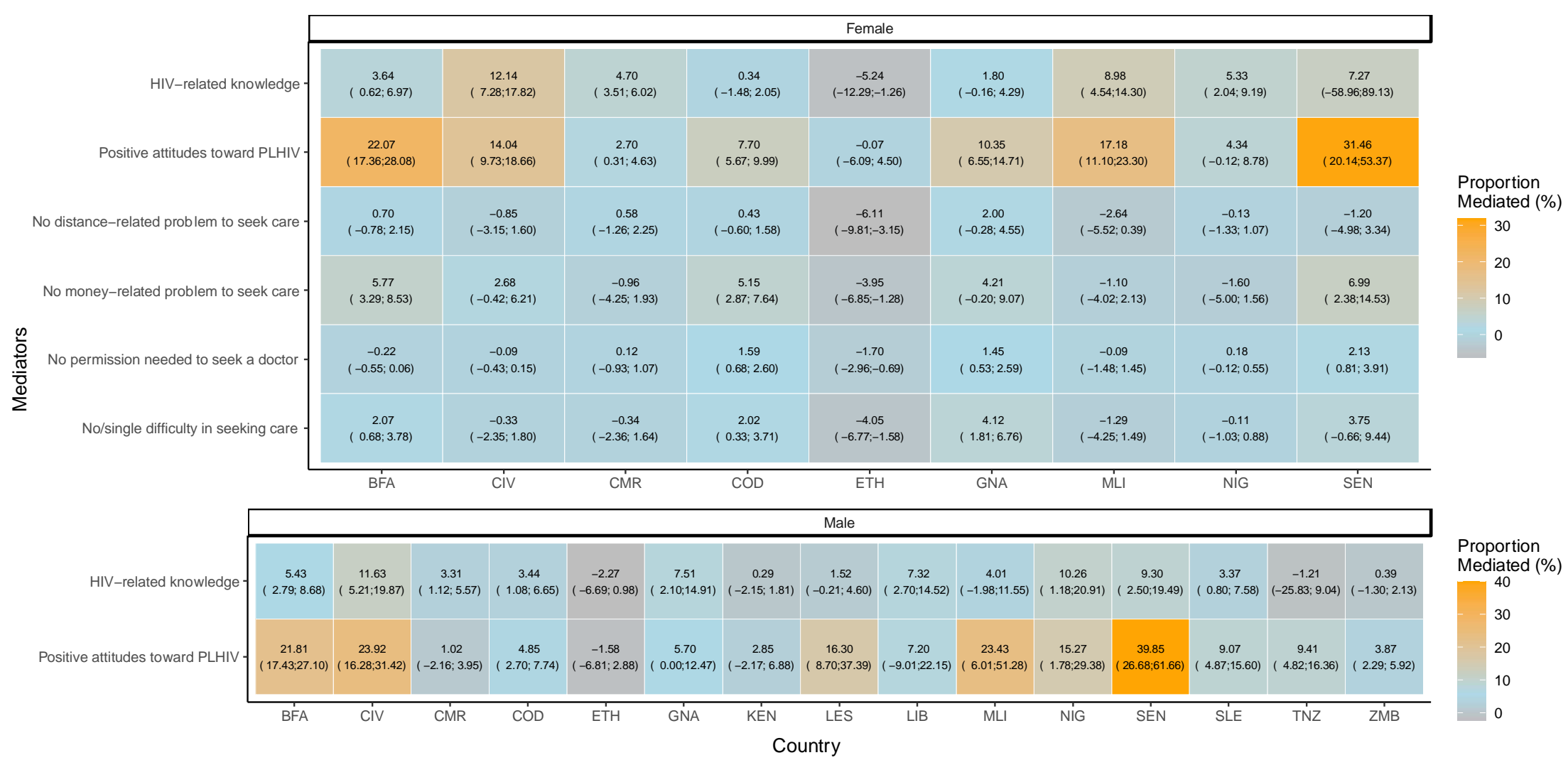

Figure 3. Heatmap of the proportion mediated by each mediator in the total effect of wealth on HIV testing, stratified by gender (eligible models). Refer to Table 1 for full country names. 


\section{Discussion}

We analysed cross-sectional population-based surveys to assess the drivers of wealth-related inequalities in recent HIV testing uptake through mediation analysis in 18 SSA countries. Richest individuals were more likely to have been recently tested than the poorest with magnitudes varying across countries. We pre-identified several participant's characteristics that could play a mediating role between wealth and recent uptake of HIV testing. The richest were more likely to have a favourable situation regarding these mediators (e.g., better knowledge about HIV, lesser stigma towards PLHIV and lesser problems to seek care) and these mediators were also positively associated with HIV testing. For instance, people having no problem to seek care were also more likely to have been recently tested for HIV. We found no single, strong mediator in the pathway between wealth and recent testing that was consistently strong across all countries and genders, but our results show that inequalities were mediated more by demand(characterizes individual's ability to perceive need for and inclination to seek health care) more than supply-side (ability to reach, pay for and engage in health care) characteristics. The importance of each mediator varied greatly by country and gender which may depend on several factors such as social, economic, epidemiology, donor and political structures of the country. This illustrates the importance of tailoring HIV testing programs to local context of the country and the needs of each gender.

Mediation analysis was conducted in countries where substantial levels of pro-rich wealthrelated inequalities were observed, majority of which were WCA countries which is consistent to studies using different inequality estimates [6,25]. This is quite expected since most WCA countries' health care delivery is through private sectors and often has inadequate decentralization of HIV services [26]. In ESA, on the other hand, health care delivery is mostly based on public and community health efforts incorporated with international donor funding [27]. Participants were also more likely to report having comprehensive HIV-related knowledge and positive attitudes toward PLHIV in ESA. This could be due to the longer history of HIV programs in this region in response to the higher burden of the epidemic. Inequalities were also found to be higher among men which could be explained by women having more access to HIV testing through routine offer in antenatal clinics as part of the prevention of mother-to-child transmission programs [28]. 
medRxiv preprint doi: https://doi.org/10.1101/2021.09.18.21263768; this version posted October 22, 2021. The copyright holder for this preprint (which was not certified by peer review) is the author/funder, who has granted medRxiv a license to display the preprint in perpetuity.

It is made available under a CC-BY-NC-ND 4.0 International license .

Countries with low uptake of recent testing tended to have high levels of inequalities with mediators having lower proportions mediated except for positive attitudes toward PLHIV. This may mean that attitudes toward PLHIV still plays a major role in explaining HIV testing inequalities regardless of the HIV epidemic in a country. HIV stigma has been well documented to be associated with higher SEP [29] and HIV testing uptake in the lifetime [30]. Stigma as an important mediator has implications for HIV testing. Due to the negative attitude towards PLHIV and the fear of being treated similarly, people may refuse to participate in any HIV prevention services or activities despite their knowledge [31]. It is also important to note that HIV-related knowledge and positive attitudes toward PLHIV do not influence testing uptake independently from each another based on an additional analysis using joint mediators approach (Table S5) [32]. In exploring the combined effects of the mediators, the mean of the individual specific PM should thus be considered instead of their sum for it will overestimate the combined proportions mediated of the mediators. This also applies to the supply-related mediators.

A study found that long travel times needed to reach healthcare in rural areas were found to be an important barrier in reaching $90 \%$ treatment coverage [33] and distance to care was found to affect uptake of facility delivery [34]. However, our findings showed that reporting no distancerelated problem in seeking care mediated a lower proportion of the relationship between wealth and recent HIV testing uptake among women. We did not use physical distance itself but the perception that distance would be a problem in seeking care and in some countries like Senegal, HIV services reach the populations through both fixed and mobile strategies reinforced by mobile screening units [35]. Although magnitude is small, reporting no money-related problem in seeking care tended to have higher proportions mediated in WCA countries which have a widespread policy of user fees for health services [26]. In most countries, married women do not usually need spousal consent legally to access sexual and reproductive health facilities [36] making no permission needed from spouse/partner to seek a doctor mediate less.

The absence of a strong mediator that we could potentially control to reduce inequalities in recent testing across all countries and genders may be due to the fact these inequalities stem from country-level, rather than individual-level factors. Indeed a study found that upstream interventions such as structural interventions, provision of resources and fiscal interventions, 
among others, tended to reduce inequalities [37]. Meanwhile, downstream interventions such as media campaigns that focus only on individual factors like education were ineffective in reducing inequalities and were more likely to increase them [37].

This study has several limitations. First, the lack of a variable capturing risk perception of acquiring HIV in the DHS. A study found that risk perception is indeed an important mediator between peer education and HIV testing in key populations [38]. Second, the issue of temporality due to the cross-sectional nature of the data, especially for the demand-related mediators. Since counselling is part of HIV testing, we cannot exclude reverse causality between these demandrelated mediators and HIV testing uptake. Another limitation is the self-report of HIV testing and mediators. A study, however, showed that the sensitivity of self-reported HIV testing ranged from $96 \%$ to $99 \%$ [39]. Despite this, reporting bias may still be present resulting to underreporting of sensitive information such as attitudes toward PLHIV. Another potential limitation is that inequalities have been measured only through wealth index which carries its own limits. Although asset-based wealth index is said to be stable and represents long-term SEP especially in LMIC, it can only assess relative wealth within a population [40]. For this reason, we did not pool the estimates across countries. Survey years were also different which may have contributed to the heterogeneity in inequality estimates and mediated effects.

Despite the limitations, this study has several strengths. We used large, standardized and nationally representative data. Moreover, to our knowledge, this is the first study to present a comprehensive dashboard of mediators in 18 sub-Saharan African countries. Importantly, compared to a classic mediation analysis, we used the potential outcomes framework allowing us to account for exposure-mediator interaction.

\section{Conclusions}

Overall, the lack of an identified strong, single mediator illustrates that inequalities may not be addressed by solely acting upon a single factor but must be tackled upstream with social and structural interventions that address the root cause of the problem. Although, we were not able to identify a single strong mediator, we were able to underline the use of mediation analysis based on the potential outcomes framework in assessing socioeconomic inequalities in HIV testing. 
medRxiv preprint doi: https://doi.org/10.1101/2021.09.18.21263768; this version posted October 22, 2021. The copyright holder for this preprint (which was not certified by peer review) is the author/funder, who has granted medRxiv a license to display the preprint in perpetuity. It is made available under a CC-BY-NC-ND 4.0 International license.

More research is needed to explore other potential mediators and contextual factors. Beyond measuring inequalities in HIV testing, we need to understand the determinants of inequalities in HIV testing to direct specific interventions that could reduce inequalities and meet the needs of everyone. 


\section{Competing interests}

We declare no competing interests.

\section{Authors' contributions}

PAAT, LT and KJ conceived and discussed the study with input from TB. PAAT and MH collated and processed the DHS. PAAT conducted the analysis with inputs from TB, LT and KJ. PAAT produced output figures and tables with inputs from LT and KJ. All authors contributed to the interpretation of the results. PAAT wrote the initial draft with inputs from LT and KJ. All authors contributed to subsequent revisions.

\section{Acknowledgements}

This study was funded by INSERM-ANRS (France Recherche Nord and Sud Sida-HIV Hépatites), grant number ANRS 12377-B104.

Disclaimer: Funding agency had no role in the study design, data collection and analysis.

\section{Additional files}

Additional file 1: Supplementary material

Description:

Figure S1. Categorization of the mediators.

Table S1. Construction and coding of the mediators.

Text S1. Formulas based on Valeri and Vanderweele to estimate the Control Direct Effect. Natural Indirect Effect, Total Effect and Proportion mediated.

Table S2. Survey and population characteristics, by country and gender.

Table S3. Path from exposure to mediator. Adjusted prevalence ratios of favorable levels of the mediator between the richest and poorest participants while accounting for confounders.

Figure S2. Path from mediator to outcome. Proportion of HIV testing uptake among the favorable and unfavorable levels of the mediator in 18 sub-Saharan African countries, stratified by gender.

Table S4. Path from mediator to outcome. Adjusted prevalence ratios of recent HIV testing between favorable and unfavorable levels of the mediators, while accounting for confounders.

Figure S3. Forest plot of the Total Effect and Controlled Direct Effect by mediator and gender. 
medRxiv preprint doi: https://doi.org/10.1101/2021.09.18.21263768; this version posted October 22, 2021. The copyright holder for this preprint (which was not certified by peer review) is the author/funder, who has granted medRxiv a license to display the preprint in perpetuity. It is made available under a CC-BY-NC-ND 4.0 International license.

Table S5. Proportion mediated by individual and joint mediators, stratified by gender, in 18 subSaharan African countries. 


\section{References}

1. UNAIDS. UNAIDS Data 2020 [Internet]. 2020 p. 29. Available from:

https://www.unaids.org/sites/default/files/media_asset/2020_aids-data-book_en.pdf

2. Programme commun des Nations Unies sur le VIH/SIDA, Organisation mondiale de la santé. Guidance on provider-initiated HIV testing and counselling in health facilities. ... Geneva: UNAIDS $\square$ : World Health Organization; 2007.

3. Cremin I, Cauchemez S, Garnett GP, Gregson S. Patterns of uptake of HIV testing in sub $\square$ Saharan Africa in the pre $\square$ treatment era. Trop Med Int Health [Internet]. 2012 Aug [cited 2021 May 31];17(8). Available from: https://onlinelibrary.wiley.com/doi/10.1111/j.1365-3156.2011.02937.x

4. Sartorius B, VanderHeide JD, Yang M, Goosmann EA, Hon J, Haeuser E, et al. Subnational mapping of HIV incidence and mortality among individuals aged 15-49 years in sub-Saharan Africa, 2000-18: a modelling study. Lancet HIV. 2021 Jun;8(6):e363-75.

5. Giguère K, Eaton JW, Marsh K, Johnson LF, Johnson CC, Ehui E, et al. Trends in knowledge of HIV status and efficiency of HIV testing services in sub-Saharan Africa, 2000-20: a modelling study using survey and HIV testing programme data. Lancet HIV. 2021 May;8(5):e284-93.

6. Ante-Testard PA, Benmarhnia T, Bekelynck A, Baggaley R, Ouattara E, Temime L, et al. Temporal trends in socioeconomic inequalities in HIV testing: an analysis of cross-sectional surveys from 16 sub-Saharan African countries. Lancet Glob Health. 2020 Jun;8(6):e808-18.

7. Jean K, Anglaret X, Moh R, Lert F, Dray-Spira R. Barriers to HIV Testing in Côte d'Ivoire: The Role of Individual Characteristics and Testing Modalities. Braitstein P, editor. PLoS ONE. 2012 Jul 18;7(7):e41353.

8. Kirakoya-Samadoulougou F, Jean K, Maheu-Giroux M. Uptake of HIV testing in Burkina Faso: an assessment of individual and community-level determinants. BMC Public Health. 2017 Dec;17(1):486.

9. Wabiri N, Taffa N. Socio-economic inequality and HIV in South Africa. BMC Public Health. 2013 Dec;13(1):1037.

10. Erena AN, Shen G, Lei P. Factors affecting HIV counselling and testing among Ethiopian women aged 15-49. BMC Infect Dis. 2019 Dec;19(1):1076.

11. Staveteig S, Croft TN, Kampa KT, Head SK. Reaching the 'first 90': Gaps in coverage of HIV testing among people living with HIV in 16 African countries. Graham SM, editor. PLOS ONE. 2017 Oct 12;12(10):e186316.

12. Kobeissi L, El Kak FH, Khawaja M, Khoshnood K. HIV/AIDS-Related Knowledge and Its Association With Socioeconomic Status Among Women: Results of Lebanese Survey for Family Health (PAPFAM) 2004. Asia Pac J Public Health. 2015 Mar;27(2):NP734-45.

13. Dadi TK, Feyasa MB, Gebre MN. HIV knowledge and associated factors among young Ethiopians: application of multilevel order logistic regression using the 2016 EDHS. BMC Infect Dis. 2020 Dec;20(1):714. 
14. Kyei-Nimakoh M, Carolan-Olah M, McCann TV. Access barriers to obstetric care at health facilities in sub-Saharan Africa—a systematic review. Syst Rev. 2017 Dec;6(1):110.

15. Corsi DJ, Neuman M, Finlay JE, Subramanian S. Demographic and health surveys: a profile. Int J Epidemiol. 2012 Dec 1;41(6):1602-13.

16. USAIDS TDP. Protecting the Privacy of DHS Survey Respondents [Internet]. Available from: https://dhsprogram.com/Methodology/Protecting-the-Privacy-of-DHS-Survey-Respondents.cfm

17. Rutstein S, Johnson K. The DHS wealth index. Calverton, MD: ORC Macro; 2004.

18. Levesque J-F, Harris MF, Russell G. Patient-centred access to health care: conceptualising access at the interface of health systems and populations. Int J Equity Health. 2013;12(1):18.

19. Yelland LN, Salter AB, Ryan P. Performance of the Modified Poisson Regression Approach for Estimating Relative Risks From Clustered Prospective Data. Am J Epidemiol. 2011 Oct 15;174(8):984-92.

20. Rubin DB. Causal Inference Using Potential Outcomes: Design, Modeling, Decisions. J Am Stat Assoc. 2005 Mar;100(469):322-31.

21. Valeri L, VanderWeele TJ. "Mediation analysis allowing for exposure-mediator interactions and causal interpretation: Theoretical assumptions and implementation with SAS and SPSS macros": Correction to Valeri and VanderWeele (2013). Psychol Methods. 2013 Dec;18(4):474-474.

22. VanderWeele TJ. Explanation in causal inference: methods for mediation and interaction. New York: Oxford University Press; 2015. 706 p.

23. Pearl J. Interpretation and Identification of Causal Mediation [Internet]. 2014 Jun. (Psychological Methods). Available from: https://ftp.cs.ucla.edu/pub/stat_ser/r389.pdf

24. VanderWeele TJ. Policy-Relevant Proportions for Direct Effects: Epidemiology. 2013 Jan;24(1):175-6.

25. Hamidouche M, Ante Testard PA, Baggaley R, Temime L, Jean K. Monitoring socioeconomic inequalities across HIV knowledge, attitudes, behaviours and prevention: results from crosssectional surveys in 18 sub-Saharan African countries [Internet]. HIV/AIDS; 2021 Aug [cited 2021 Sep 2]. Available from: http://medrxiv.org/lookup/doi/10.1101/2021.08.24.21262532

26. UNAIDS. The Western and Central Africa Catch-Up Plan: Putting HIV treatment back on the fasttrack by 2018 [Internet]. 2017. Available from:

https://www.unaids.org/sites/default/files/media_asset/WCA-catch-up-plan_en.pdf

27. UNAIDS. Global AIDS Update 2018: Miles to Go The Response to HIV in Eastern and Southern Africa [Internet]. 2018. Available from:

https://www.unaids.org/sites/default/files/media_asset/miles-to-go_eastern-and-southernafrica_en.pdf

28. Gunn JKL, Asaolu IO, Center KE, Gibson SJ, Wightman P, Ezeanolue EE, et al. Antenatal care and uptake of HIV testing among pregnant women in sub-Saharan Africa: a cross-sectional study. J Int AIDS Soc. 2016 Jan;19(1):20605. 
29. Coleman JD, Tate AD, Gaddist B, White J. Social Determinants of HIV-Related Stigma in FaithBased Organizations. Am J Public Health. 2016 Mar;106(3):492-6.

30. Kalichman SC, Shkembi B, Wanyenze RK, Naigino R, Bateganya MH, Menzies NA, et al. Perceived HIV stigma and HIV testing among men and women in rural Uganda: a population-based study. Lancet HIV. 2020 Sep;S2352301820301983.

31. Yang H, Li X, Stanton B, Fang X, Lin D, Naar-King S. HIV-related knowledge, stigma, and willingness to disclose: A mediation analysis. AIDS Care. 2006 Oct;18(7):717-24.

32. VanderWeele TJ, Vansteelandt S, Robins JM. Effect Decomposition in the Presence of an Exposure-Induced Mediator-Outcome Confounder: Epidemiology. 2014 Mar;25(2):300-6.

33. Palk L, Okano JT, Dullie L, Blower S. Travel time to health-care facilities, mode of transportation, and HIV elimination in Malawi: a geospatial modelling analysis. Lancet Glob Health. 2020 Dec;8(12):e1555-64.

34. Kohler PK, Akullian A, Okanda J, Otieno G, Kinuthia J, Voss J, et al. Distance to HIV and Antenatal Care: A Geospatial Analysis in Siaya County, Kenya. J Assoc Nurses AIDS Care. 2019 Sep;30(5):548-55.

35. Wade AS, M. Ousmane Amadou Sy. Rapport d'évaluation de l'état de préparation à la transition et à la pérennité du Programme national de lutte contre le VIH au Sénégal [Internet]. Washington, DC $\square$ : Palladium: Health Policy Plus; 2019. Available from: http://www.healthpolicyplus.com/ns/pubs/14332-14607_RapportdEvaluationSenegal.pdf

36. UNAIDS Data 2018 [Internet]. 2021 Apr. Available from: https://www.unaids.org/sites/default/files/media_asset/unaids-data-2018_en.pdf

37. Lorenc T, Petticrew M, Welch V, Tugwell P. What types of interventions generate inequalities? Evidence from systematic reviews: Table 1. J Epidemiol Community Health. 2013 Feb;67(2):190 3.

38. Lin Y, Li C, Wang L, Jiao K, Ma W. The mediated effect of HIV risk perception in the relationship between peer education and HIV testing uptake among three key populations in China. AIDS Res Ther. 2021 Dec;18(1):8.

39. Xia Y, Milwid RM, Godin A, Boily M-C, Johnson LF, Marsh K, et al. Accuracy of self-reported HIV testing history and awareness of HIV-positive status among people living with HIV in four Sub-Saharan African countries. AIDS [Internet]. 2020 Nov 26 [cited 2021 Feb 15];Publish Ahead of Print. Available from: https://journals.lww.com/10.1097/QAD.0000000000002759

40. Howe LD, Galobardes B, Matijasevich A, Gordon D, Johnston D, Onwujekwe O, et al. Measuring socio-economic position for epidemiological studies in low- and middle-income countries: a methods of measurement in epidemiology paper. Int J Epidemiol. 2012 Jun 1;41(3):871-86. 


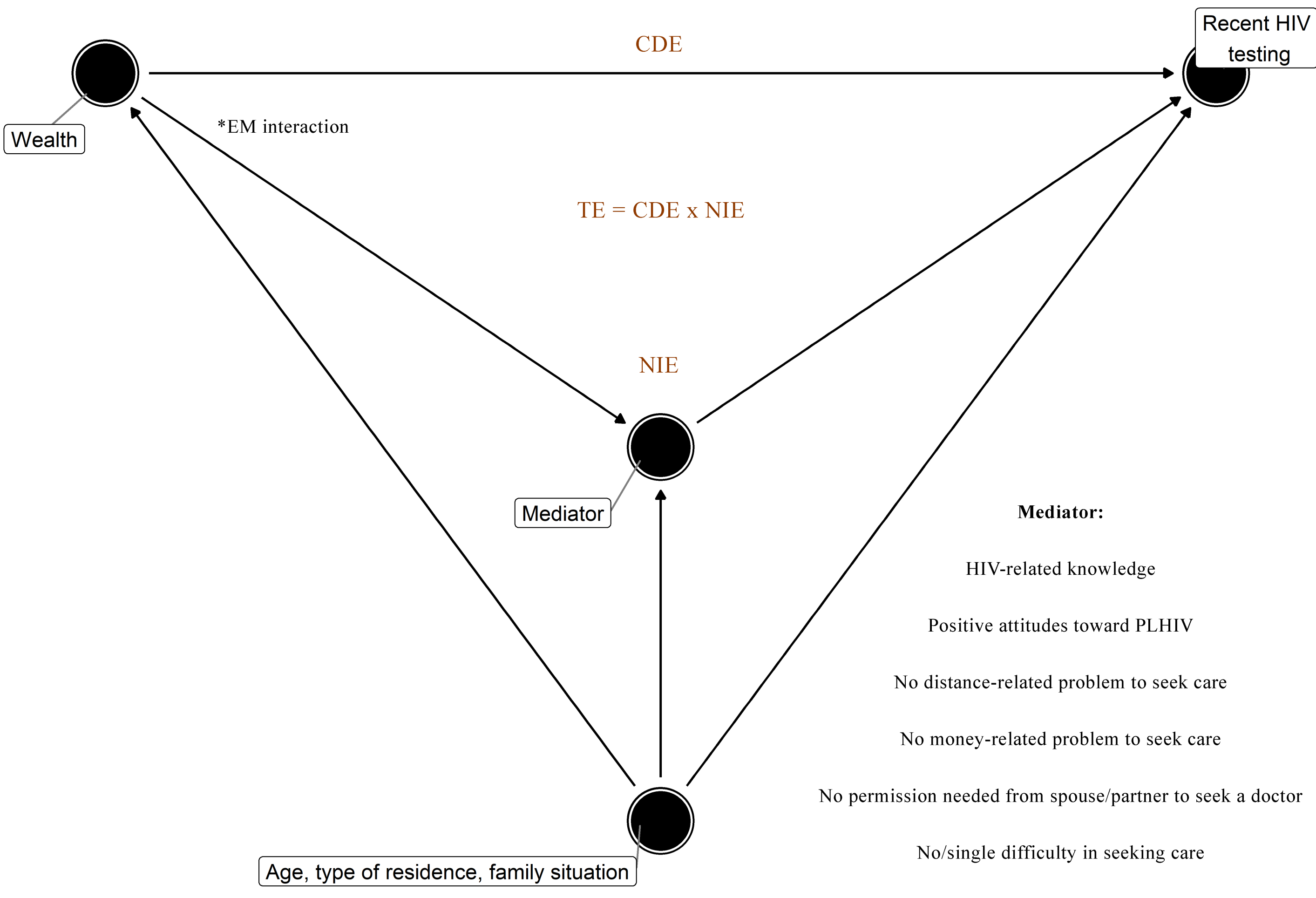



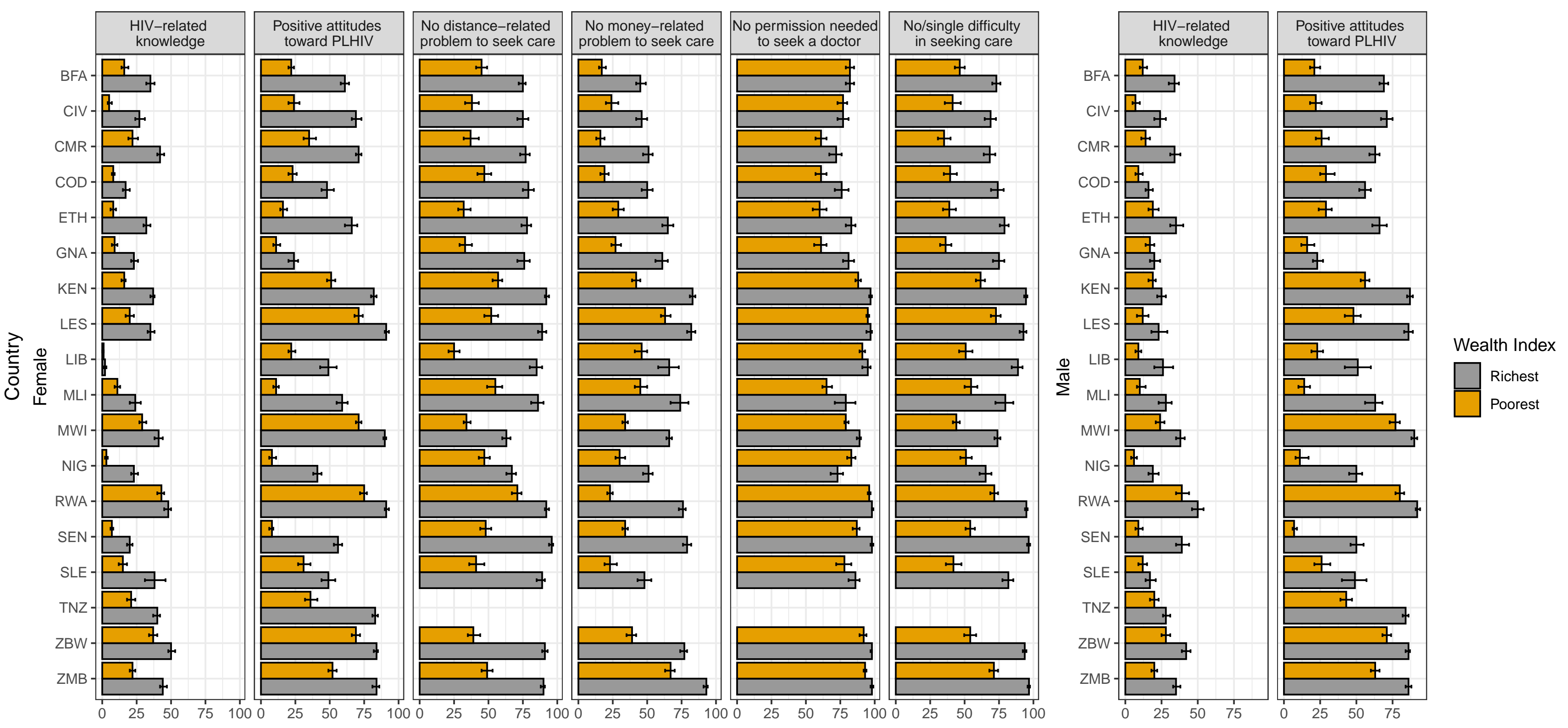

Self-reported favorable reponses by mediator between the richest and poorest participants (\%) 
